\title{
Composição florística e potencial de uso das espécies em uma área do bioma Cerrado em Bandeirantes - MS
}

Floristic composition and potential use of species in an area of the Cerrado biome in Bandeirantes MS

Composición florística y uso potencial de especies en un área del bioma Cerrado en Bandeirantes -

\begin{abstract}
Resumo
Para se conhecer com maior precisão o estoque madeireiro e a estrutura de florestas nativas, é de suma importância a identificação das espécies existentes e suas características. Desta maneira, este trabalho objetivou realizar um levantamento florestal, por amostragem aleatória simples, da composição florística em uma área do bioma Cerrado no município de Bandeirantes, Mato Grosso do Sul. A metodologia consistiu na delimitação de cinco parcelas de $10 \mathrm{x}$ 100 m, subdivididas em 25 áreas de 10 x 20 m, sendo estimadas a altura total e comercial e medido o diâmetro à altura do peito $(\geq 10 \mathrm{~cm})$ das árvores, obtendo-se o volume de madeira, sendo o fuste classificado quanto à qualidade (estaca, lenha ou serraria). O levantamento resultou em 395 indivíduos pertencentes a 21 famílias e 49 espécies. Para cada espécie foi calculado o índice do valor de importância (IVI), indicando Vochysia tucanorum (Vochysiaceae) como a espécie de maior IVI. Fabaceae foi a família mais representativa, com 12 espécies, seguida por Annonaceae, Bignoniaceae e Vochysiaceae, com três espécies cada. $\mathrm{O}$ volume total de madeira para a área foi de $3350,64 \mathrm{~m}^{3}$, sendo que 59,85\% dos indivíduos mensurados podem ser destinados à serraria, demonstrando o potencial de uso e justificando um dos motivos da antropização deste bioma.
\end{abstract}

Palavras-chave: Inventário florestal; Florística; Volume de madeira.

\begin{abstract}
In order to know more precisely the wood stock and the structure of native forests, it is very important to identify the existing species and their characteristics. Thus, this work aimed to carry out a forest survey, by simple random sampling, of the floristic composition in an area of the Cerrado biome in the municipality of Bandeirantes, Mato Grosso do Sul. The methodology consisted of the delimitation of five plots of 10 x $100 \mathrm{~m}$, subdivided into 25 areas of $10 \times 20 \mathrm{~m}$, the total and commercial height being estimated and the diameter at breast height $(\geq 10 \mathrm{~cm})$ of the trees was measured, obtaining the volume of wood, the shaft being classified according to quality (stake, firewood or sawmill). The survey resulted in 395 individuals belonging to 21 families and 49 species. The importance value index (IVI) was calculated for each species, indicating Vochysia tucanorum (Vochysiaceae) as the species with the highest IVI. Fabaceae was the most representative family, with 12 species, followed by Annonaceae, Bignoniaceae and Vochysiaceae, with three species each. The total volume of wood for the area was $3350.64 \mathrm{~m}^{3}$, of which $59.85 \%$ of the individuals measured could be destined for the sawmill, demonstrating the potential for use and justifying one of the reasons for the anthropization of this biome.
\end{abstract}

Keywords: Forest inventory; Floristics; Wood volume.

\section{Resumen}

Para conocer con mayor precisión el stock de madera y la estructura de los bosques nativos, es muy importante identificar las especies existentes y sus características. Así, este trabajo tuvo como objetivo realizar un levantamiento forestal, por muestreo aleatorio simple, de la composición florística en un área del bioma Cerrado en el municipio de Bandeirantes, Mato Grosso do Sul. La metodología consistió en la delimitación de cinco parcelas de 10 x 100 m, 
subdivididas en 25 áreas de 10 x 20 m, estimándose la altura total y comercial y se midió el diámetro a la altura del pecho $(\geq 10 \mathrm{~cm})$ de los árboles, obteniendo el volumen de madera, clasificándose el fuste según su calidad (estaca, leña o aserradero). El estudio forestal resultó en 395 individuos pertenecientes a 21 familias y 49 especies. Se calculó el índice de valor de importancia (IVI) para cada especie, indicando Vochysia tucanorum (Vochysiaceae) como la especie con el IVI más alto. Fabaceae fue la familia más representativa, con 12 especies, seguida de Annonaceae, Bignoniaceae y Vochysiaceae, con tres especies cada una. El volumen total de madera para la zona fue de $3350,64 \mathrm{~m}^{3}$, de los cuales el $59,85 \%$ de los individuos medidos podrían destinarse al aserradero, demostrando el potencial de uso y justificando una de las razones de la antropización de este bioma.

Palabras clave: Inventario forestal; Florística; Volumen de madera.

\section{Introdução}

O bioma Cerrado contém cerca de 5\% de toda a biodiversidade do planeta, sendo considerado a savana mais rica do mundo, cobrindo cerca de $22 \%$ do território brasileiro e abrangendo 12 estados, com a forma stricto sensu sendo a mais comum (Mendonça e Costa, 2018). Devido ao alto grau de antropização e número de espécies endêmicas, é considerado um dos biomas mais comprometidos do país (hotspot), tendo perdido mais da metade de sua cobertura original (Grecchi et al., 2014). Desta maneira, é importante um olhar crítico sobre as ações humanas neste bioma (Costa et al., 2020).

No Estado de Mato Grosso do Sul, ocupa a maior parte do território na forma de pequenos e médios fragmentos dispersos, sujeitos a ações antrópicas, sendo que a atividade agropecuária é a maior causadora de sua descaracterização. Além deste fator, o entorno dos fragmentos normalmente é ocupado por campos compostos por Brachiaria spp., uma espécie oportunista e invasora, o que também leva a descaracterização das áreas restantes (Oliveira \& Rezende, 2012). Entretanto, até a poucas décadas, o Cerrado era visto como terra improdutiva, devido as características químicas e físicas do solo (ácidos e distróficos), dificultando seu aproveitamento e sendo explorado principalmente para extração de lenha e carvão e criação extensiva de gado, entre outras atividades (Alho \& Martins, 1995; Costa, 2003; Mendonça \& Costa, 2018).

Apesar disto, o bioma, em sua maior parte, se caracteriza por suas áreas planas e a presença de chuvas estacionais e após a correção química do solo e introdução de novas cultivares, adaptadas ao ambiente, ocorreu sua ocupação intensiva, através da agropecuária. Esta situação permitiu a formação de grandes áreas de monoculturas, com plantio de cana-de-açúcar, milho e soja, por exemplo, além pastagens de braquiária e silvicultura (eucalipto), resultando em grande produção de grãos, carne, álcool, açúcar e madeira, entre outras commodities (Grecchhi et al., 2014).

De acordo com a legislação, a supressão vegetal de espécies nativas exige autorização de órgão ambiental, o que ocorria anteriormente através de autorizações concedidas pelo IBAMA (Instituto Brasileiro do Meio Ambiente e dos Recursos Naturais Renováveis). Todavia, devido ao grande volume de atividades, tem ocorrido a descentralização da gestão florestal, com os estados arcando com a responsabilidade sobre os procedimentos e os instrumentos relacionados ao uso sustentável, à supressão e outros usos da vegetação nativa (Brasil, 2006).

Entretanto, o conhecimento sobre as diferentes características das formações florestais encontradas nos diferentes biomas brasileiros ainda é incompleto, o que não permite conhecer todo o potencial de uso dos recursos madeireiros. Para se atingir o uso racional, segundo Moro e Martins (2011), estudos fitossociológicos são necessários, pois possibilitam análises estruturais comparativas com o mesmo conjunto de espécies, se há dominância em um local ou, uma distribuição de abundâncias de maior similaridade entre as espécies.

As variações encontradas nas áreas podem ser explicadas pela regeneração natural (sucessão), a qual segundo Reis et al. (2009), atua dentro das populações em relação à adaptação ao ambiente aliada a fatores demográficos e ecológicos. As diferentes fases de sucessão contribuem para o estabelecimento e desenvolvimento das plantas, possibilitando a preservação, conservação e formação de novas florestas (Gama et al., 2003; Monteiro \& Falcão, 2019). Desta maneira, o levantamento fitossociológico e a execução do inventário florestal são ferramentas primordiais que devem ser utilizadas no planejamento das ações de gestão ambiental para o uso racional dos recursos florestais, fornecendo informações sobre as características 
quantitativas e qualitativas da floresta (Soares et al., 2011; Kershaw Junior et al., 2016).

Diante do exposto, o presente estudo objetivou realizar por meio de inventário florestal com amostragem aleatória simples da composição florística e diversidade, o levantamento de espécies e suas características, em uma área florestal do bioma Cerrado no município de Bandeirantes, Mato Grosso do Sul.

\section{Metodologia}

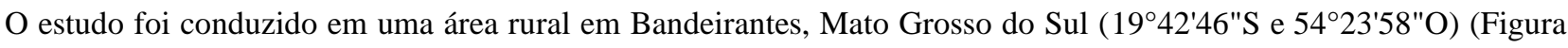
1). De acordo com Köppen e Geiger, o clima é classificado como Cwa, úmido a subúmido com precipitação pluviométrica que varia de 1500 a $1750 \mathrm{~mm}$ anuais e, temperatura média de 20,8 ${ }^{\circ} \mathrm{C}$ (SEMAC, 2011; Climate-Data, 2017).

Figura 1. Localização da área de estudo, Bandeirantes, Mato Grosso do Sul.

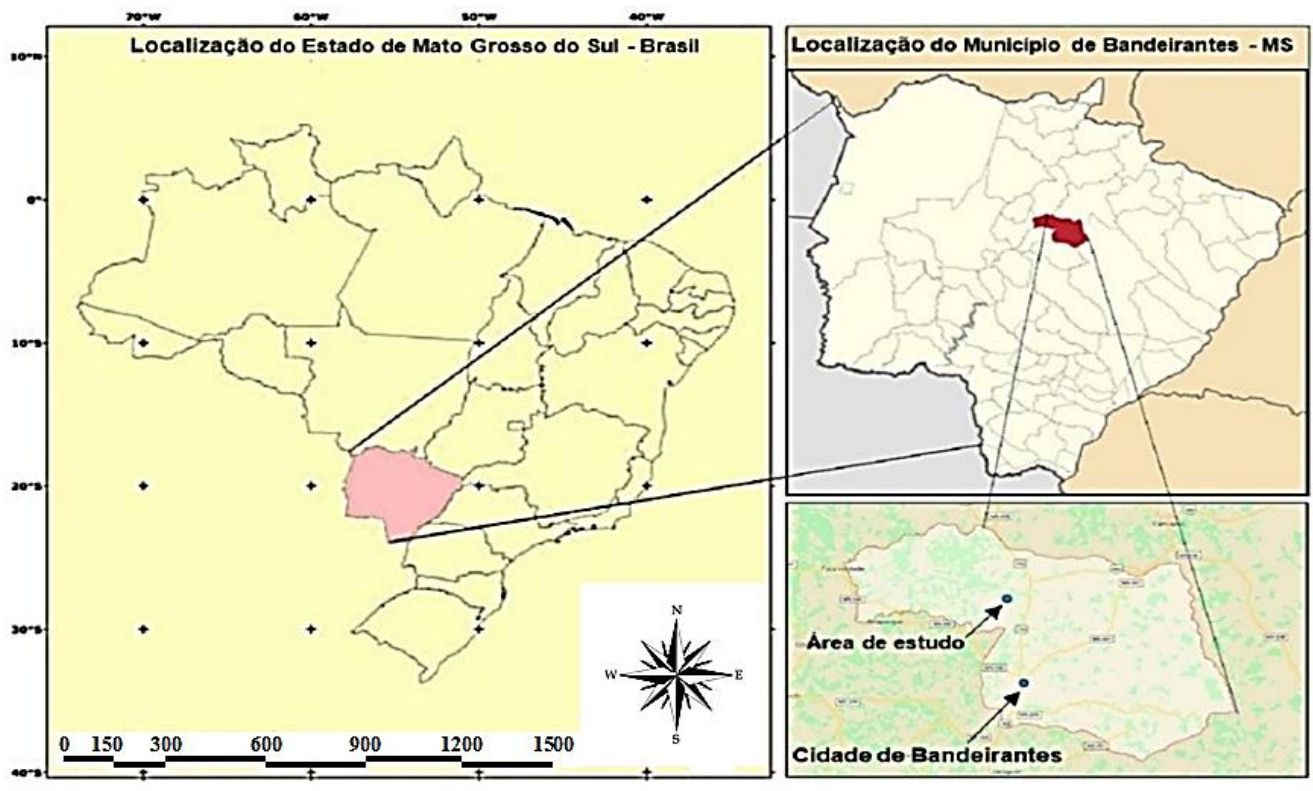

Fonte: Adaptado de IBGE (2006).

A cobertura vegetal predominante na região é de pastagens plantadas, ocorrendo fragmentos do bioma Cerrado, com a presença de cerradão (savana arbórea densa), com vegetação predominantemente arbórea, cerrado stricto sensu (cerrado), fisionomia predominantemente arbóreo-arbustivo e, formação campestre (campo cerrado), um tipo de vegetação constituída de pequenas árvores, arbustos e gramíneas, representando uma forma mais baixa e menos densa do Cerrado (Ribeiro \& Walter, 2008). Os diferentes tipos de vegetação ocorrem em solos classificados como Latossolos Vermelhos, Latossolos VermelhoAmarelos e Neossolos Quartzarênicos, de baixa fertilidade natural, altos níveis de óxidos de ferro e alumínio e valores acentuados de areia.

A metodologia consistiu na delimitação de cinco parcelas de 10 x $100 \mathrm{~m}\left(1000 \mathrm{~m}^{2}\right)$ distribuídas ao acaso, subdivididas em 25 áreas de 10 x $20 \mathrm{~m}\left(200 \mathrm{~m}^{2}\right)$, localizadas através de GPS modelo Garmin Etrex. As árvores localizadas dentro das parcelas foram identificadas quanto à família, gênero e espécie, sendo que indivíduos com diâmetro a altura do peito igual ou superior a 10,0 cm (medido através de suta) tiveram sua altura total e comercial, estimadas.

O fuste foi classificado quanto à qualidade, sendo retilíneo (serraria), levemente tortuoso (poste ou estaca) e tortuoso ou danificado (lenha). O volume estimado de madeira foi calculado através do produto da área basal, altura e fator de forma $(0,65)$, baseado em metodologia adaptada por Elias (2009). As espécies também foram identificadas quanto ao seu tipo 
sucessional (pioneira, secundária e clímax) e forma de dispersão de sementes (anemocórica, autocórica e zoocórica), de acordo com Martins (2004) e Lorenzi $(2016 ; 2020)$. Para cada espécie foi calculado o índice de valor de importância (IVI), obtido através da frequência relativa e absoluta, dominância relativa e absoluta e, densidade relativa e absoluta, de acordo com BraunBlanquet (1979), Mueller-Dombois e Ellenberg (2003), e Durigan (2006).

\section{Resultados e Discussão}

Na área foram quantificados 395 indivíduos, distribuídos em 49 espécies (sete indeterminadas) de 21 famílias (Quadro 1). Os resultados encontrados, em termos de famílias e espécies, foram inferiores aos citados por Camilotti et al. (2011), em estudo na mesma região, que identificaram 2118 indivíduos distribuídos em 33 famílias, 66 gêneros e 82 espécies. Entretanto, os autores citados utilizaram como fator de inclusão DAP igual ou maior que $5 \mathrm{~cm}$, o que permitiu a inserção de um maior número de árvores.

Quadro 1. Famílias, espécies, número de indivíduos (NI), altura (H m), diâmetro a altura do peito (DAP cm), volume de madeira $\left(\mathrm{V} \mathrm{m}^{3}\right.$ ), e índice de valor de importância (IVI) de espécies encontradas em área do bioma Cerrado, Bandeirantes, Mato Grosso do Sul.

\begin{tabular}{|c|c|c|c|c|c|c|c|}
\hline Família & Espécie & Nome popular & NI & $\mathbf{H}$ & DAP & $\mathbf{V}$ & IVI \\
\hline \multicolumn{8}{|l|}{ Annonaceae } \\
\hline & Annona crassiflora Mart. (S) (Z) (FM) & Marôlo & 12 & 8,1 & 21,6 & 2,75 & 9,7 \\
\hline & $\begin{array}{l}\text { Duguetia lanceolata A. St.-Hil. (PS) (Z) (*) } \\
\qquad(\mathrm{FM})(\delta \delta)\end{array}$ & Pindaíva & 2 & 6,8 & 13,1 & 0,13 & 1,8 \\
\hline & $\begin{array}{l}\text { Xylopia aromatica (Lam.) Mart. (PS) (Z) }(*) \\
(\mathrm{M})(\delta)\end{array}$ & Pimenta-de-macaco & 22 & 6,8 & 11,7 & 1,15 & 13,5 \\
\hline \multicolumn{8}{|l|}{ Apocynaceae } \\
\hline & $\begin{array}{c}\text { Aspidosperma macrocarpon Mart. (C) (An) }(*) \\
(* * * V U)(\mathrm{M})(\delta \delta)\end{array}$ & Guatambu & 10 & 7,7 & 19,5 & 2,68 & 8,7 \\
\hline \multicolumn{8}{|l|}{ Bignoniaceae } \\
\hline & $\begin{array}{l}\text { Handroanthus heptaphyllus (Mart.) Mattos (C) } \\
\qquad(\mathrm{An})(*)(\mathrm{M})(\delta \delta)\end{array}$ & Ipê-roxo & 3 & 8,0 & 18,3 & 0,49 & 2,8 \\
\hline & Jacaranda cuspidifolia Mart. (P) (A) (M) $(\delta \delta)$ & Carobinha & 2 & 10,5 & 39,8 & 1,86 & 2,8 \\
\hline & $\begin{array}{l}\text { Tabebuia aurea (Manso) Benth. \& Hook. fil. ex } \\
\text { S. Moore (S) (An) (M) }(\delta \delta)\end{array}$ & Ipê-amarelo & 6 & 7,8 & 22,7 & 1,49 & 5,6 \\
\hline \multicolumn{8}{|l|}{ Calophyllaceae } \\
\hline & Kielmeyera rubriflora Cambess (S) (An) (M) & Pau-santo & 4 & 6,8 & 18,1 & 0,49 & 3,3 \\
\hline \multicolumn{8}{|l|}{ Caryocaraceae } \\
\hline & Caryocar brasiliense A.St.-Hil. (PS) (Z) $(*)(\mathrm{F})$ & Pequi & 7 & 6,2 & 18,6 & 1,45 & 6,2 \\
\hline \multicolumn{8}{|l|}{ Chrysobalanacea } \\
\hline & Licania humilis Cham. \& Schltdl. (S) (Z) (FM) & Oiti-do-campo & 1 & 4,5 & 12,4 & 0,04 & 0,9 \\
\hline Combretaceae & & & & & & & \\
\hline
\end{tabular}


Terminalia corrugata (Ducke) Gere \& Boatwr.

$(\mathrm{S})(\mathrm{Z})(\mathrm{FM})(\delta \delta)$

$\begin{array}{llllll}\text { Tarumarana } & 11 & 7,6 & 18,6 & 2,22 & 9,6\end{array}$

\begin{tabular}{|c|c|c|c|c|c|c|c|}
\hline Dilleniaceae & & & & & & & \\
\hline & Curatella americana L. (P) (Z) (M) & Lixeira & 1 & 6,5 & 26,1 & 0,24 & 0,8 \\
\hline & Davilla elliptica St.-Hil. (P) (Z) (M) & Lixeirinha & 1 & 7,5 & 10,8 & 0,05 & 0,9 \\
\hline \multicolumn{8}{|l|}{ Ebenaceae } \\
\hline & Diospyros hispida A. DC. (S) (Z) (*) (FM) & Olho-de-boi & 7 & 7,6 & 23,1 & 1,84 & 5,8 \\
\hline \multicolumn{8}{|l|}{ Euphorbiaceae } \\
\hline & Maprounea guianensis Aubl. (S) (An) (M) & Marmelinho & 1 & 7,0 & 11,8 & 0,05 & 0,9 \\
\hline \multicolumn{8}{|l|}{ Fabaceae } \\
\hline & $\begin{array}{l}\text { Anadenanthera colubrina (Vell.) Brenan (P) } \\
(\mathrm{Au})(\mathrm{M})(\delta \delta)\end{array}$ & Angico branco & 1 & 7,0 & 26,4 & 0,27 & 1,1 \\
\hline & $\begin{array}{l}\text { Anadenanthera peregrina }(\text { Benth.) Altschul (P) } \\
\qquad(\mathrm{Au})(\mathrm{M})(\delta \delta)\end{array}$ & Angico-preto & 10 & 8,5 & 19,0 & 2,07 & 8,2 \\
\hline & Andira cujabensis Benth. (S) (Z) (M) & Andira & 10 & 8,2 & 18,8 & 1,90 & 8,2 \\
\hline & $\begin{array}{l}\text { Bowdichia virgilioides Kunth (PS) (An) } \\
\qquad(* * * \mathrm{VU})(* * \mathrm{QA})(\mathrm{M})(\delta \delta)\end{array}$ & Sucupira & 1 & 11,5 & 33,4 & 0,706 & 1,2 \\
\hline & $\begin{array}{l}\text { Dalbergia miscolobium Benth. (P) (An) }(* * \mathrm{QA}) \\
(\delta)\end{array}$ & Caviúna-do-cerrado & 16 & 9,2 & 25,8 & 6,39 & 13,3 \\
\hline & Dipteryx alata $\operatorname{Vogel}(\mathrm{C})(\mathrm{Z})(*)(\mathrm{FM})(\delta \delta)$ & Cumbaru & 20 & 8,2 & 19,3 & 4,47 & 14,3 \\
\hline & Diptychandra aurantiaca Tul. (P) (Z) ( $\delta \delta)$ & Balsaminho & 10 & 6,1 & 15,5 & 0,92 & 7,3 \\
\hline & Erythrina velutina Willd. (S) (An) (M) & Suinã & 4 & 7,3 & 21,9 & 0,80 & 3,5 \\
\hline & $\begin{array}{l}\text { Hymenaea stigonocarpa Hayne. (C) }(\mathrm{Z})(* * \mathrm{QA}) \\
(\mathrm{FM})(\delta \delta)\end{array}$ & Jatobá-do-cerrado & 7 & 8,4 & 27,6 & 2,84 & 6,6 \\
\hline & Morfoespécie 2 (Fabaceae Cascuda) & Indeterminada & 6 & 6,6 & 17,1 & 0,78 & 4,3 \\
\hline & $\begin{array}{l}\text { Plathymenia reticulata Benth. (C) (An) }(*)(\mathrm{M}) \\
\qquad(\delta \delta)\end{array}$ & Vinhático & 10 & 5,7 & 13,7 & 0,75 & 7,5 \\
\hline & $\begin{array}{c}\text { Stryphnodendron adstringens (Mart.) Coville } \\
(\mathrm{P})(\mathrm{Au})(*)(\mathrm{M})\end{array}$ & Barbatimão & 2 & 5,5 & 11,3 & 0,08 & 1,3 \\
\hline
\end{tabular}

\begin{tabular}{|c|c|c|c|c|c|c|c|}
\hline Lauraceae & & & & & & & \\
\hline & $\begin{array}{c}\text { Nectandra megapotamica (Sprengel) Mez (PS) } \\
(\mathrm{Z})(\mathrm{M})(\delta \delta)\end{array}$ & Canelinha & 5 & 7,2 & 15,9 & 0,60 & 4,1 \\
\hline \multicolumn{8}{|l|}{ Malpighiaceae } \\
\hline & Byrsonima basiloba A. Juss. (PS) (Z) (F) & Murici & 6 & 8,0 & 19,9 & 1,14 & 5,4 \\
\hline \multicolumn{8}{|l|}{ Malvaceae } \\
\hline & $\begin{array}{l}\text { Pseudobombax tomentosum (Mart. \& Zucc) A. } \\
\text { Robyns (C) (An) }(*)(* * * V U)\end{array}$ & Embiruçu & 1 & 6,0 & 18,5 & 0,11 & 1,0 \\
\hline
\end{tabular}


Pleroma granulosum (Desr.) D. Don (S) (An)

$(\delta \delta)$

$\begin{array}{llllll}\text { Quaresmeira } & 16 & 6,1 & 12,9 & 0,92 & 11,3\end{array}$

\begin{tabular}{|c|c|c|c|c|c|c|c|}
\hline Meliaceae & & & & & & & \\
\hline & $\begin{array}{l}\text { Guarea guidonia (L.) Sleum. (S) (Z) }(* * \mathrm{QA}) \\
(\mathrm{M})(\delta \delta)\end{array}$ & Marinheiro & 16 & 6,5 & 15,6 & 1,60 & 9,2 \\
\hline & Trichilia pallida Sw. (S) (Z) (M) $(\delta \delta)$ & Catiguá & 29 & 8,2 & 16,0 & 3,77 & 18,6 \\
\hline \multicolumn{8}{|l|}{ Moraceae } \\
\hline & Ficus insipida Willd. (P) (Z) (FM) & Figueira mata-pau & 2 & 7,0 & 13,5 & 0,15 & 1,8 \\
\hline & Morfoespécie 1 & Indeterminada & 3 & 8,2 & 19,2 & 0,49 & 5,5 \\
\hline & Morfoespécie 3 & Indeterminada & 2 & 6,5 & 12,7 & 0,12 & 1,7 \\
\hline & Morfoespécie 4 & Indeterminada & 3 & 10,8 & 28,1 & 1,74 & 3,3 \\
\hline & Morfoespécie 5 & Indeterminada & 1 & 9,5 & 36,0 & 0,68 & 3,4 \\
\hline & Morfoespécie 6 & Indeterminada & 3 & 10,2 & 22,4 & 0,90 & 3,0 \\
\hline & Morfoespécie 7 & Indeterminada & 2 & 4,8 & 11,9 & 0,07 & 1,3 \\
\hline & Morfoespécie 8 & Indeterminada & 1 & 11,0 & 21,7 & 0,28 & 1,0 \\
\hline
\end{tabular}

Psidium cattleianum Afzel. ex Sabine (P) (Z)

(FM)

Araçá vermelho $\quad 8 \quad 6,2 \quad 13,3 \quad 0,60 \quad 6,1$

Psidium grandifolium Mart. ex DC. (P) (Z) (*)

(FM)

Araçazinho $\quad 2 \quad 8,0 \quad 14,6 \quad 0,21 \quad 1,8$

\begin{tabular}{|c|c|c|c|c|c|c|c|}
\hline Rubiaceae & & & & & & & \\
\hline & $\begin{array}{l}\text { Alibertia edulis (Rich.) A. Rich. ex DC. (P) (Z) } \\
\text { (FM) }\end{array}$ & Marmelo & 6 & 5,1 & 11,5 & 0,23 & 3,8 \\
\hline & $\begin{array}{l}\text { Rudgea viburnoides (Cham.) Benth. (S) (Z) (M) } \\
\qquad(\delta)\end{array}$ & Cotó & 22 & 3,9 & 13,3 & 0,96 & 13,6 \\
\hline
\end{tabular}

\begin{tabular}{|c|c|c|c|c|c|c|c|}
\hline Urticaceae & & & & & & & \\
\hline & Cecropia pachystachya Trec. (P) (Z) (M) & Embaúba & 3 & 9,2 & 15,5 & 0,45 & 2,3 \\
\hline \multicolumn{8}{|l|}{ Vochysiaceae } \\
\hline & Qualea grandiflora Mart. (PS) (An) (M) $(\delta)$ & Pau-terra & 27 & 7,9 & 20,8 & 6,23 & 21,2 \\
\hline & Qualea multiflora Mart. (P) (An) (M) & Cinzeiro & 9 & 6,8 & 17,7 & 1,33 & 7,6 \\
\hline & Vochysia tucanorum Mart. (PS) (An) (M) $(\delta)$ & Pau-doce & 41 & 6,9 & 15,5 & 4,83 & 23,6 \\
\hline
\end{tabular}

$(*)=$ menos preocupante; $(* * \mathrm{QA})=$ Quase ameaçada; $(* * * V U)=$ vulnerável $) ;(\mathrm{C})=$ Clímax; $(\mathrm{P})=$ Pioneira; $(\mathrm{PS})=$ Formação primária/secundária; $(\mathrm{S})=$ Formação secundária; $\delta=$ espécies de valor madeireiro (menor valor); $\delta \delta=$ espécies de valor madeireiro (maior valor $(\mathrm{F})=$ frutífera; $(\mathrm{FM})=$ frutífera/medicinal; $(\mathrm{M})=$ medicinal; $(\mathrm{An})=$ Anemocoria; $(\mathrm{Au})=$ Autocórica; e, $(\mathrm{Z})=$ Zoocoria. Fonte: Autores.

Mediante o levantamento, os resultados apontaram que a família Fabaceae foi, quantitativamente, a mais representativa, com 12 espécies $(57,14 \%$ ) (uma não identificada), perfazendo 24,56\% do total dos indivíduos. Bezerra et al. (2020), em trabalho na região da Chapada do Araripe, Crato - Ceará, também identificaram Fabaceae possuindo a maior riqueza de espécies, demonstrando sua importância no bioma Cerrado. Resultado similar foi apresentado por Camilotti et al. (2011), na mesma região, com o predomínio de Fabaceae. De acordo com Rodrigues et al. (2004), a riqueza e densidade de 
Fabaceae pode decorrer da capacidade de muitas espécies da família rebrotar a partir de raízes. Além disto, muitas espécies têm capacidade de fixar nitrogênio, o que é importante na colonização de solos pobres (Martins, 1993).

Vochysiaceae, apesar de contribuir com apenas 3 espécies, juntamente com Annonaceae e Bignoniaceae (42,86\% do total), apresentou o segundo maior número de indivíduos (21,1\%), e a espécie com mais indivíduos, Vochysia tucanorum (10,4\% do total). Fabaceae é a segunda maior família de Angiospermas em importância econômica, com plantas possuindo valor alimentício, ornamental e madeireiro (Lewis, 2000). Além disto, a presença de metabólitos secundários, como os compostos fenólicos, dentre outras estruturas químicas, tem grande relevância, permitindo seu uso medicinal e na produção e fabricação de gomas, corantes, espessantes e resinas (Lewis et al., 2005).

Segundo Bridgewater et al. (2004), a forma lenhosa do Cerrado é composta, comumente, por pequenos grupos de famílias dominantes e as famílias encontradas na região de Bandeirantes são as mais ricas em espécies em outros levantamentos, como por exemplo, em trabalhos de Weiser e Godoy (2001), Silva et al. (2002), Camilotti et al. (2011) e Lopes et al. (2011). A exceção é Annonaceae, não mencionada com frequência como dominante, apesar de Silveira (2010), em estudo florístico em área indígena no Noroeste de Mato Grosso, mencionar Annonaceae e Vochysiaceae com boa representatividade. Camilotti et al. (2011) também relataram Annonaceae como uma das famílias mais abundantes em Bandeirantes. Estudos de Silva et al. (2002), Balduino et al. (2005), Santos e Vieira (2005) e Camilotti et al. (2011) confirmam que além de Vochysiaceae, a família Fabaceae também é importante em áreas de Cerrado. Estas duas famílias totalizaram $43,05 \%$ do IVI total, totalizando $44,05 \%$ dos indivíduos amostrados.

Outras famílias tiveram menor representatividade de espécies como, Dilleniaceae, Meliaceae, Myrtaceae e Rubiaceae (duas) e, Apocynaceae, Caryocaraceae, Chrysobalanaceae, Calophyllaceae, Combretaceae, Ebenaceae, Euphorbiaceae, Lauraceae, Malpighiaceae, Malvaceae, Melastomataceae, Moraceae e Urticaceae, com apenas uma espécie (Figura 2).

As oito famílias que mais se destacaram correspondem a 28,57\% do total e contribuíram com 29 espécies (59,18\% da riqueza florística) e 77,47\% do número de indivíduos da área. Individualmente, V. tucanorum (Vochysiaceae) apresentou maior número de indivíduos (41), seguido T. pallida (Meliaceae) (29), Q. grandiflora (Vochysiaceae) (27), R. viburnoides (Rubiaceae) e X. aromatica (Annonaceae) (22) e, D. alata (Fabaceae), com 20 indivíduos.

Oito espécies apresentaram um IVI acima de dez, representando 48,86\% do total de indivíduos. Dentre estas, Qualea grandiflora e Vochysia tucanorum, consideradas pioneiras e/ou secundárias, apresentaram os maiores valores devido ao grande número de indivíduos na área, além de valores altos de DAP. Camilotti et al. (2011) em estudos na mesma região, também citaram Qualea parviflora, Qualea grandiflora, Rudgea viburnoides e Xylopia aromatica como sendo as espécies de maior IVI, resultados similares aos encontrados por este trabalho. Estes resultados corroboram os estudos de Silva et al. (2002), Santos e Vieira (2005), Silveira (2010) e Camilotti et al. (2011), que confirmam que Vochysiaceae possui um dos maiores valores de IVI no Cerrado. Este fator é relacionado ao fato de muitas espécies possuírem a capacidade de absorver alumínio do solo, sem gerar problemas ao seu desenvolvimento, levando-se em consideração que este elemento é tóxico para a maioria das plantas (Haridasan e Araújo, 1988). 
Figura 2. Representação das famílias por número de espécie e de indivíduos em uma área do bioma Cerrado, Bandeirantes, Mato Grosso do Sul.
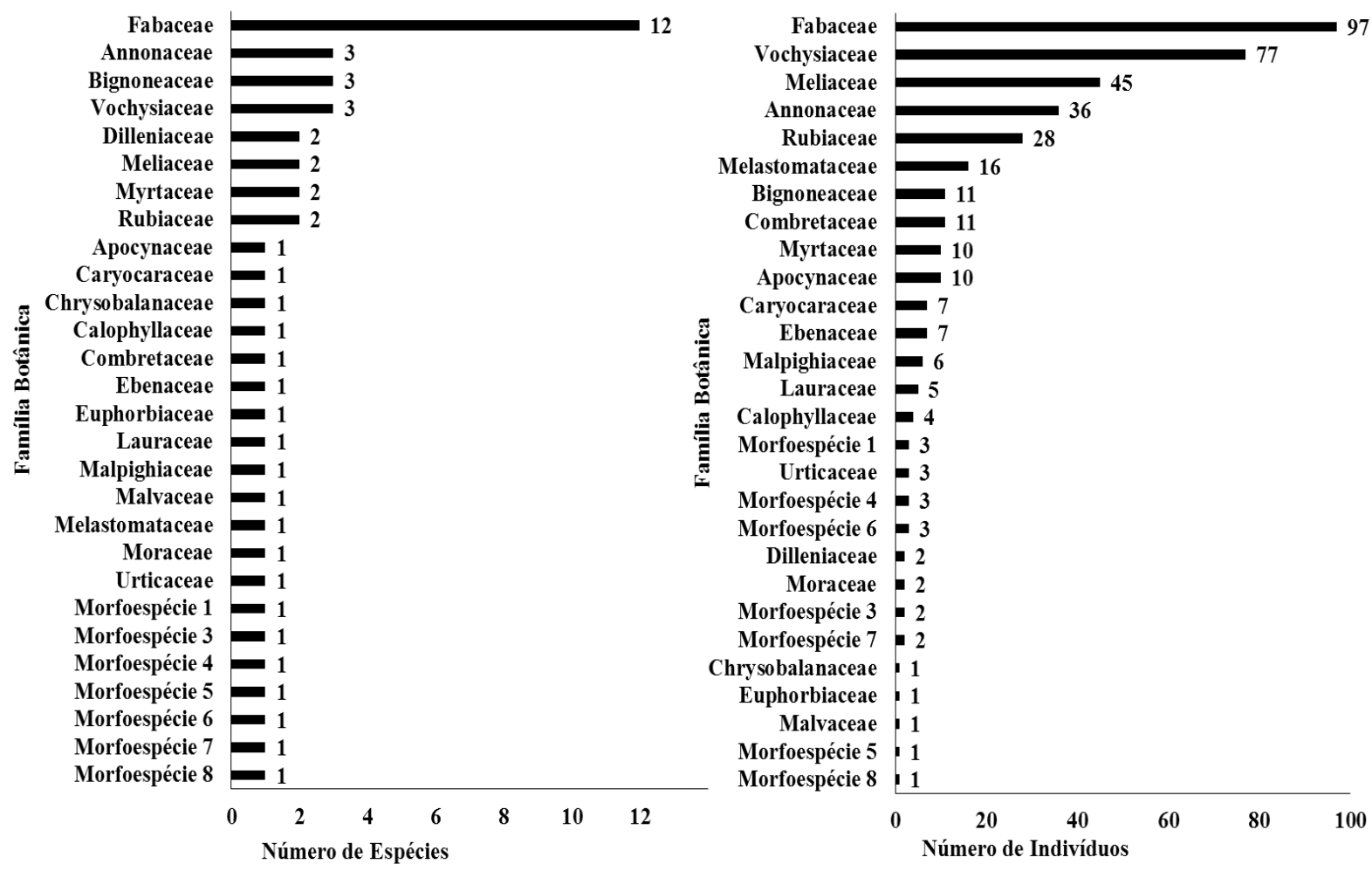

Fonte: Autores.

De acordo com Felfili et al. (2004), a presença ou ausência de espécies demonstra a semelhança na composição florística dos Cerrados, levando em consideração suas densidades, pois estas áreas estão sujeitas às variações espaciais e temporais na organização e manutenção das comunidades. Ainda, segundo os autores, a influência de fatores bióticos (polinização, dispersão e herbivoria, por exemplo) e abióticos (fogo, solo e pluviosidade, por exemplo), bem como aos fatores históricos (ação antrópica), determinam a estrutura de cada formação vegetacional.

As espécies classificadas como pioneiras, segundo Martins (2004) e Lorenzi (2016; 2020), foram 13 (J. cuspidifolia, C. americana, D. elliptica, A. colubrina, A. peregrina, D. miscolobium, D. aurantiaca, S. adstringens, F. insipida, P. cattleyanum, A. edulis, C. pachystachya e Q. multiflora), pertencentes a sete famílias (68 indivíduos), equivalendo a 17,21\% do total de indivíduos. Este grupo é conhecido por ser pouco exigente e em geral, seus indivíduos crescem rápido, propiciando sombra e dando condições para outras espécies mais exigentes germinarem e se desenvolverem. Suas sementes são pequenas, facilmente dispersadas pelo vento e água (Peres, 2016; Sartorelli e Campos Filho, 2017). Neste estudo, a forma de dispersão anemocórica está representada por 37,72\% dos indivíduos, zoocórica por 52,66\% e autocórica, apenas 3,29\%, resultado similar ao citado por Camilotti et al. (2011), na mesma região.

Estes resultados indicam que ocorre a predominância de espécies com dispersão animal, um indicativo que a área apresenta boas condições ecológicas, propiciando interações entre espécies, além da presença de animais dispersores. Oliveira et al. (2014), em trabalho em um fragmento de Cerrado em Campo Grande - MS, também avaliaram que a ocorrência de espécies com dispersão zoocórica era um indicativo da conservação da área, resultando em uma grande diversidade. De acordo com Reis e Kageyama (2003), Silva (2003), e Moraes et al. (2013), a presença da fauna dispersora de sementes aumenta 
naturalmente a diversidade vegetal, permitindo a chegada de sementes de outras áreas e mantendo o fluxo gênico, além de manter os processos ecológicos.

A presença de espécies encontradas em formações primárias e secundárias, tais como D. lanceolata, X. aromatica, C. brasiliense, B. virgilioides, N. megapotamica, B. basiloba, Q. grandiflora e V. tucanorum (Martins, 2004; Lorenzi, 2016; 2020), pertencentes a seis famílias (111 indivíduos - 28,1\%), demonstra que a área é bem preservada, apesar de processos sucessionais relacionados a uma provável retirada seletiva de madeira.

Espécies de formações secundárias, como A. crassiflora, T. aurea, K. rubriflora, L. humilis, T. corrugata, D, hispida, M. guianensis, A. cujabensis, E. velutina, P. granulosum, G. guidonia, T. pallida e R. viburnoides (Martins, 2004; Lorenzi, 2016; 2020), pertencentes a 11 famílias (139 indivíduos - 35,19\%), são outro indicativo de supressão vegetal ocorrida no passado. As espécies secundárias têm crescimento mais lento que as pioneiras e possuem maior densidade de madeira e altura, além de tempo de vida mais longo, sendo mais valorizadas para uso da madeira (Davide et al., 1995).

De acordo com Peres (2016) e Sartorelli e Campos Filho (2017), o processo de regeneração natural se dá em núcleos, que se iniciam sob algumas plantas pioneiras, geralmente zoocóricas, como as árvores dos gêneros Alibertia, Byrsonima, Caryocar, Cecropia, Curatella, Davilla, Duguetia, Diptychandra, Ficus, Nectandra, Psidium e Xylopia. Esta situação demonstra a importância da diversidade vegetal e os processos que podem ser causados pela retirada seletiva de determinadas espécies.

Por outro lado, a presença de espécies clímax, tais como A. macrocarpon, H. heptaphyllus, D. alata, H. stigonocarpa, $P$. reticulata e $P$. tomentosum (Lorenzi, 2016; 2020), pertencentes a quatro famílias (51 indivíduos - 12,91\% do total), indicam que a supressão de vegetação é antiga e/ou ocorreu de forma parcial. Este grupo cresce preferencialmente sob o dossel de outras árvores e leva mais tempo para se desenvolver, além de atingir maior tempo de vida, ocorrendo no interior da mata primária e nas formações secundárias, em condições ambientais mais estáveis. Sua madeira é normalmente resistente e boa qualidade, a chamada madeira de lei, possuindo a espécie maior tamanho, em altura e diâmetro (Davide et al., 1995).

De acordo com Hahn et al. (2007), Martinelli e Moraes (2013), SNA (2016) e CNCFlora (2018), nove espécies (D. lanceolata, X. aromatica, A. macrocarpon, H. heptaphyllus, C. brasiliense, D. hispida, D. alata, P. reticulata e P. grandifolium), pertencentes a seis famílias (75 indivíduos - 18,99\% do total) presentes na área, estão na lista vermelha de espécies ameaçadas, porém, com situação de menor preocupação. Ainda segundo os autores, três espécies (B. virgilioides, $D$. miscolobium e G. guidonia) de duas famílias (39 indivíduos - 9,95\% do total) estão quase ameaças de extinção. Outras duas (A. macrocarpon e P. tomentosum), pertencentes a outras duas famílias (11 indivíduos - 2,79\% do total), estão quase ameaçadas para região, porém, vulnerável para outras regiões.

As espécies com madeira de valor comercial foram contabilizadas em 22, pertencentes a dez famílias (297 indivíduos - 75,19\% do total). Destas, 17 espécies (sete famílias, 143 indivíduos - 36,2\% do total) possuem maior valor econômico para comercialização, sendo 13 aptas para serraria, em um total de 121 indivíduos (30,63\%); dez podem ser destinadas para postes e esticadores (72 indivíduos - 18,23\% do total); e, sete espécies para lenha (67 indivíduos - 16,96\% do total). As demais, com menor valor econômico, apresentaram números de 40, 55 e 40 indivíduos para serraria, postes e lenha, respectivamente. Martinelli e Moraes (2013) e Silva (2014) observam que a população de algumas espécies de distribuição ampla sofre com a redução de seus hábitats, principalmente, devido a agricultura e queimadas, reduzindo seu potencial de uso.

Entre as plantas frutíferas, duas espécies (Annona crassiflora e Psidium cattleianum) pertencentes a duas famílias (13 indivíduos - 3,29\% do total) se destacam. Segundo Coradin et al. (2011), são plantas alimentícias de interesse, em função dos usos e potencialidades para pesquisas futuras. Apesar de não constarem de lista de ameaçadas, ocorre redução significativa de suas populações, devido à coleta indiscriminada de seus frutos ainda imaturos, o que implica na diminuição de regeneração natural, além da diminuição de seu hábitat natural. Os frutos são utilizados para consumo in natura ou para preparar sorvetes, 
sucos, geleias, licores, bolachas e, recheio de bolos e bombons, possuindo quantidades relevantes de vitamina A, C e complexo B, além de antioxidantes e carotenoides.

Vinte e quatro espécies pertencentes a 12 famílias (240 indivíduos - 60,76\%) são conhecidas como medicinais e destas, 11 espécies de oito famílias (78 indivíduos - 19,75\%) são também árvores frutíferas, com uso na culinária regional (Rizzini, 1978; Mattos, 1979; Rizzini \& Mors, 1995; Jácome et al., 2010; Lorenzi, 2016; 2020; Useful Tropical Plants, 2019). A utilização de plantas do bioma Cerrado para fins medicinais, alimentares e na confecção de peças de artesanato é comum, embora, de acordo com Rondon Neto et al. (2010), ainda exista pouca valorização das espécies do bioma.

Em relação à diversidade fitoquímica, as plantas do Cerrado oferecem uma fonte riquíssima de moléculas de diferentes classes de metabólitos secundários, ainda pouco exploradas (Silva et al., 2010). Gottlieb e Borin (1994) e Saccaro Júnior (2011) demonstraram que a diversidade química é muito grande, sendo que uma das maneiras de se extrair valor econômico da biodiversidade é a bioprospecção, comprovando o potencial de uso do bioma. Entre as espécies com estudos relacionados a compostos secundários podem ser citadas Davilla elliptica (Jácome et al., 2010), Caryocar brasiliense (Lopes et al., 2011), Psidium cattleianum (Alvarenda et al., 2015), Alibertia edulis (Valli et al., 2016), Annona crassiflora (Silva et al., 2016) e Hymenaea stigonocarpa (Menezes Filho \& Castro, 2019), entre outras.

Em relação à altura, todos os indivíduos amostrados variaram entre 2 a 17 m, com o maior número nas classes de 4-10 m (334), representando 84,55\% do total; 21 indivíduos (5,31\%) apresentaram altura entre 10-17 m, sendo o mais alto a morfoespécie 4, com 17 m, encontrada em área mais fechada, indicando preservação e/ou maior nível de fertilidade do solo (Figura 3). Os resultados indicam que em alguns locais, com solos de menor fertilidade e/ou ação antrópica, ocorreu o maior número de indivíduos, $40(10,13 \%)$ com a menor altura, variando de 2-4 m. Dentre as classes que se destacam, as árvores com altura entre 7 e 8 metros apresentaram maior porcentagem de indivíduos (19,75\%), e somados às alturas de 8-9 (12,91\%), 9-10 $(13,16 \%)$, e acima de $10 \mathrm{~m}(5,32 \%)$, totalizam 51,14\% de indivíduos. Estes resultados são similares aos citados por Camilotti et al. (2011) na mesma região, com altura do estrato arbóreo oscilando entre 3 e $7 \mathrm{~m}$ e presença de algumas árvores emergentes, atingindo até 18 , indicando um padrão para a região em estudo.

De acordo com Ribeiro e Walter (2008), a fitofisionomia do cerradão (fisionomia florestal) apresenta dossel contínuo e cobertura arbórea que pode oscilar de 50 a 90\%, com altura média variando de 8 a 15 metros, podendo atingir até 20 m, o que foi encontrado na área de estudo, demonstrando que o local pode ser considerado um cerradão típico. 
Figura 3. Frequência das classes de altura das espécies indivíduos ${ }^{-1}$ em área do bioma Cerrado, Bandeirantes, Mato Grosso do Sul.

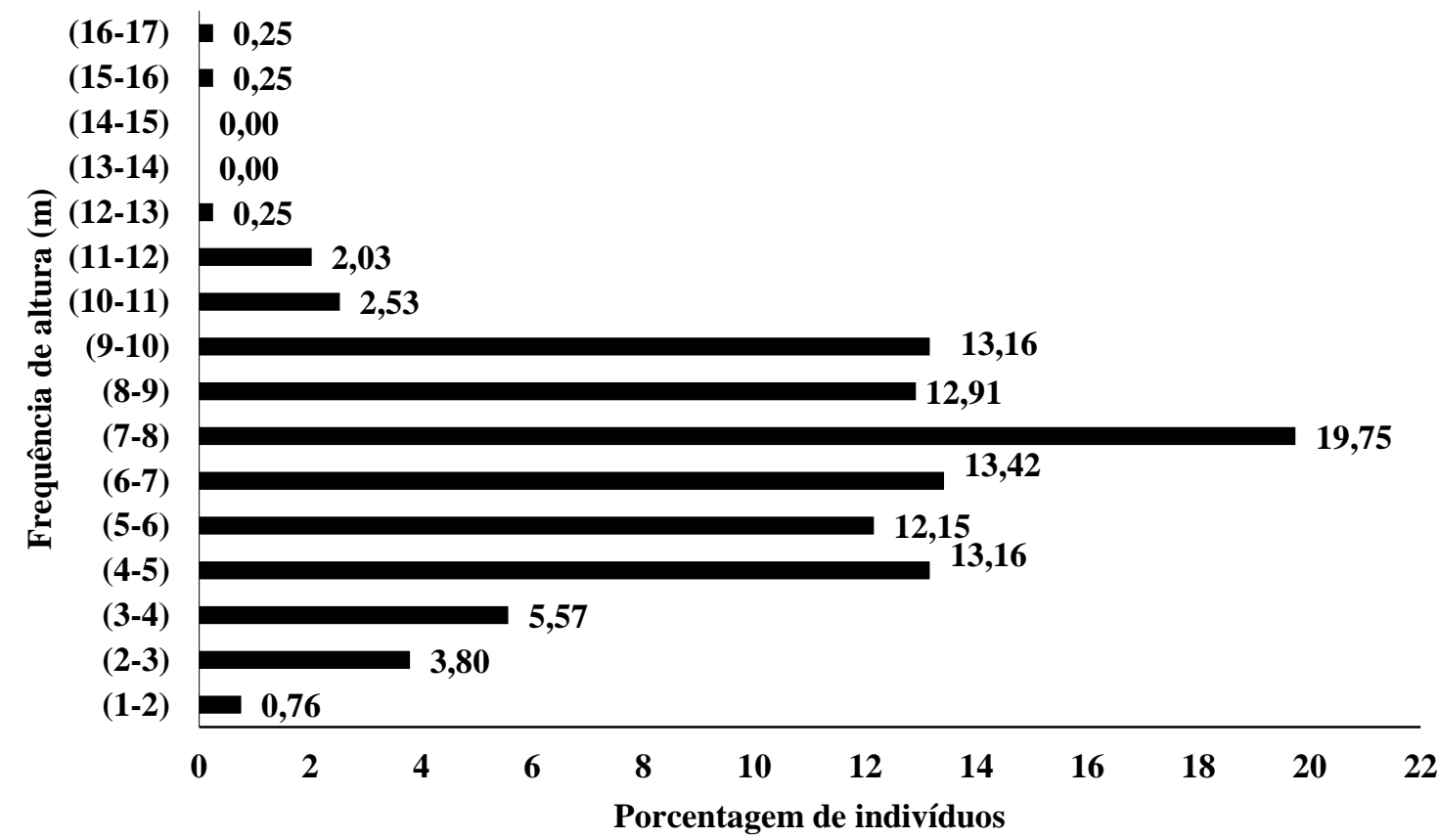

Fonte: Autores.

A distribuição diamétrica (DAP) dos indivíduos apresentou uma tendência decrescente, comumente conhecida no setor florestal como J-invertido, onde $52,91 \%$ dos maiores diâmetros estão localizados na primeira classe de 10 a $15 \mathrm{~cm}$ (Figura 4), resultado similar ao apresentado por Camilotti et al. (2011), em que a maioria dos indivíduos (91\%) se encontra nas duas primeiras classes de diâmetro (entre cinco e $15 \mathrm{~cm}$ ), em uma curva de distribuição J invertido.

Hymenaea stigonocarpa foi a espécie com maior diâmetro $(49 \mathrm{~cm})$, sendo comum em áreas de Cerrado (Durigan et al., 1998). De acordo com Carvalho (2007), a espécie na idade adulta atinge dimensões próximas de $20 \mathrm{~m}$ de altura e $50 \mathrm{~cm}$ de DAP. Elias (2009) trabalhando com inventário florestal no bioma Cerrado em Paranã, Tocantins, observou que $63 \%$ dos maiores diâmetros estavam localizados na classe de 7 a $12 \mathrm{~cm}$. As diferenças na composição florística entre determinadas áreas estão relacionadas a variações espaciais e temporais. A influência de fatores bióticos e abióticos, bem como os fatores históricos, determinam a estrutura de cada comunidade (Felfili et al., 2004). 
Figura 4. Frequência das classes diamétricas (DAP) das espécies indivíduos ${ }^{-1}$ em área do bioma Cerrado, Bandeirantes, Mato Grosso do Sul.

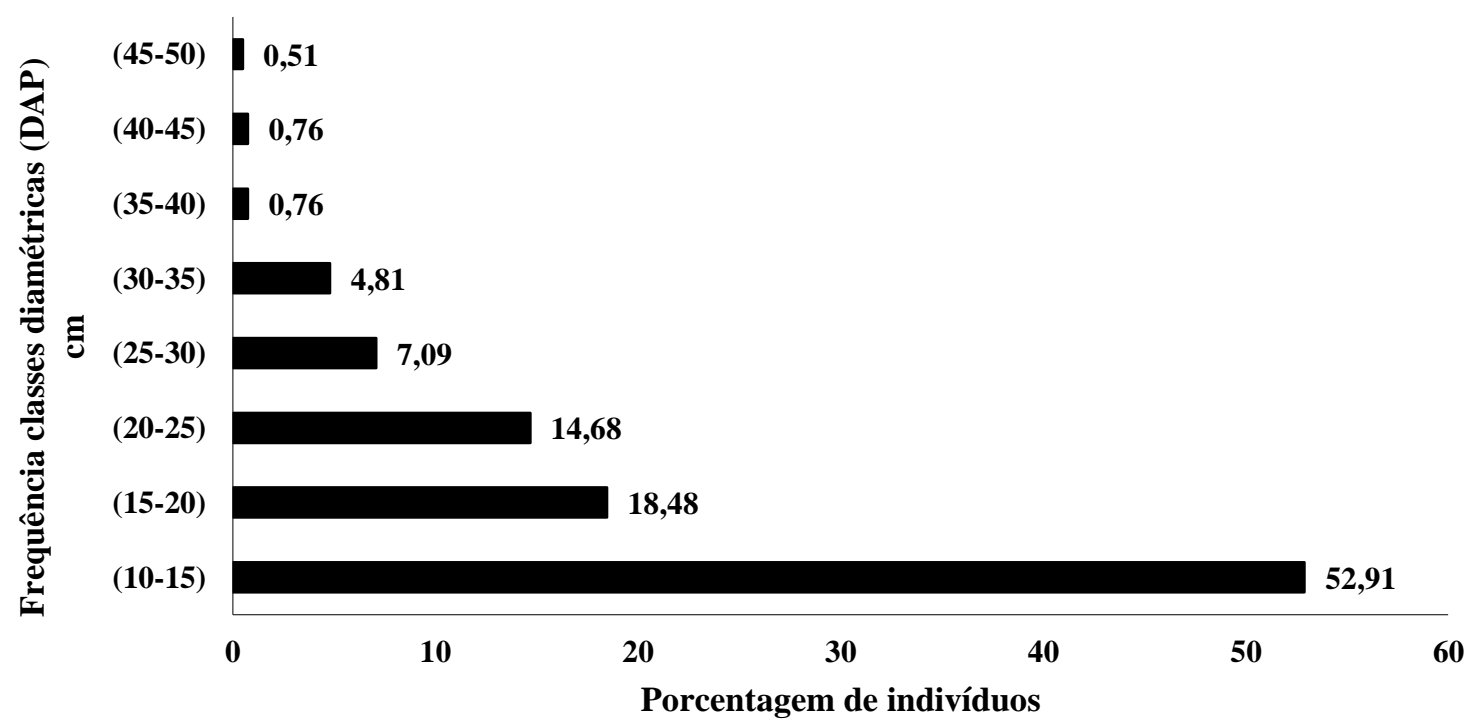

Fonte: Autores.

A correlação entre os diâmetros e as alturas das árvores (Figura 5) indica que a dispersão das alturas em torno dos diâmetros é bem característica de floresta preservada, devido à variedade de espécies e tamanhos. Ou seja, a floresta pode ser considerada inequiânea, composta por indivíduos pertencentes a várias idades. De acordo com Husch et al. (1982), a relação hipsométrica observada, que descreve a relação entre o diâmetro e a altura, indica a posição sociológica das árvores, composta por classes diferentes, com um aumento na altura sendo acompanhado de maior diâmetro, característica de florestas com menor grau de perturbação.

Figura 5. Relação entre DAP e altura das espécies em área do bioma Cerrado, Bandeirantes, Mato Grosso do Sul.

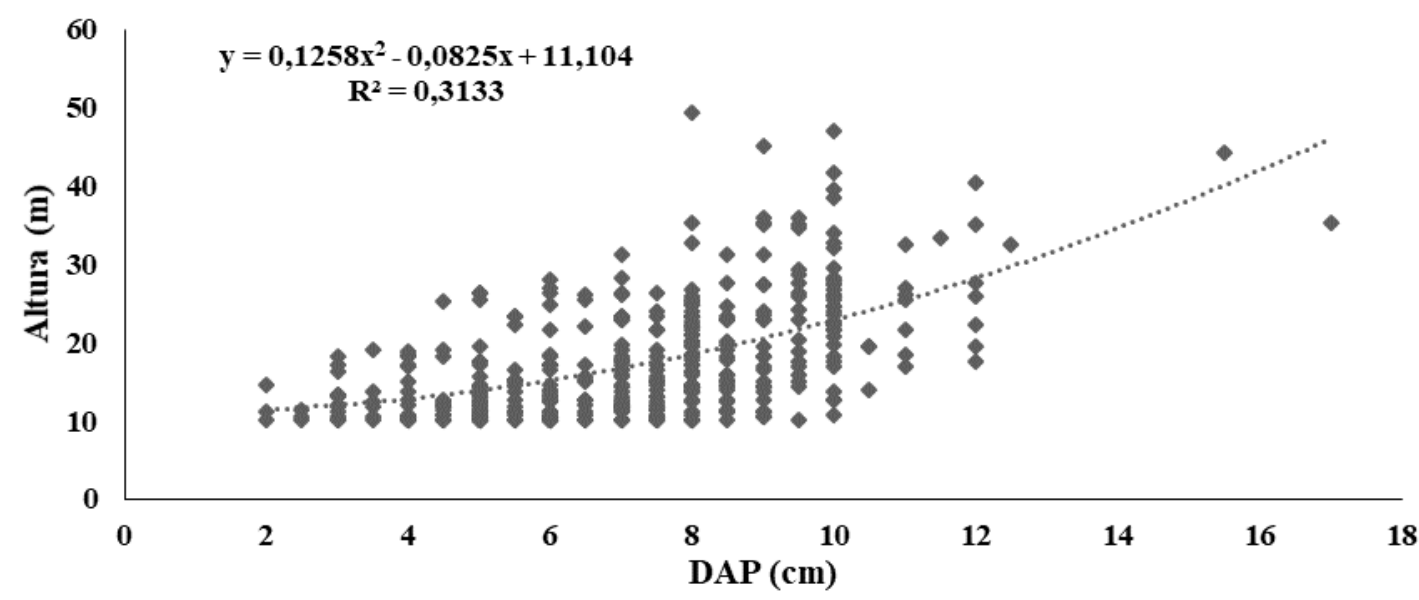

Fonte: Autores.

Os dados obtidos demonstram que a área avaliada, apesar das ações antrópicas que provavelmente ocorreram no passado, possui um processo de sucessão avançado, com parte de seus indivíduos sendo jovens, com DAP entre 10 e 15 cm; porém a altura, entre 4 e $10 \mathrm{~m}$, indica que o crescimento é contínuo, com a formação possuindo um determinado tempo de desenvolvimento. Desta maneira, pode-se concluir que ela apresenta características de uma formação secundária desenvolvida, 
com os dados relacionando altura e diâmetro indicando esta situação, com o maior número de indivíduos localizado na parte central da dispersão (Figura 5). Rocha (2011) constatou em estudo sobre estimativa de volume e biomassa da vegetação lenhosa de floresta estacional de Goiás, que 90\% da comunidade arbórea amostrada encontrava-se entre 5 a $10 \mathrm{~cm}$ de DAP, com valores de altura variando de 1,5 a $18 \mathrm{~m}$.

Hack et al. (2005), Felfili et al. (2007), Siqueira et al. (2009), Lima et al. (2010), e Lima et al. (2014), em trabalhos realizados em áreas de Cerrado, encontraram maiores valores de DAP para as árvores estudadas. As diferenças observadas provavelmente estão relacionadas ao nível de antropização das áreas e o tempo de regeneração natural a que todas estão submetidas, indicando que a área de Bandeirantes está em um processo sucessional mais recente.

É comum em regiões rurais que os proprietários retirem das matas a madeira necessária para a construção de cercas, currais e outras obras civis, buscando as árvores de maior porte. Após esta retirada, aos poucos a vegetação que permaneceu no local inicia o processo de sucessão secundária, recuperando em determinado período, suas características originais. Desta maneira, uma retirada ocasional não iria significar a desestruturação total da formação vegetacional e sim, uma aceleração de processos relacionados a sucessão vegetal, normalmente. Porém, o que ocorre, após esta retirada seletiva e recuperação da área, é um novo processo de desmatamento, de forma mais completa, levando a perda das características da formação, pois também ocorre a venda de madeira para produção de carvão, por exemplo, eliminando-se toda a vegetação arbórea de valor.

Este processo pode ser visualizado através da contabilização do volume total de madeira na área, igual a $67,0128 \mathrm{~m}^{3}$, correspondente à 3350,64 $\mathrm{m}^{3} \mathrm{ha}^{-1}$ (Tabela 1), com a existência de madeira que pode ser destinada a serraria, fabricação de postes e esticadores e, como lenha. Os volumes de madeira total e comercial, estimados para toda a área, corresponderam a cerca de $40,11 \mathrm{~m}^{3}$, ou seja, $59,85 \%$, oriundos de 14 espécies e 260 indivíduos que possuem altura superior a 10 metros; o restante das espécies (35), com 135 indivíduos, totalizaram 26,9028 $\mathrm{m}^{3}$ (40,15\%).

Tabela 1. Estimativa do volume e qualificação do material lenhoso em área do bioma Cerrado, Bandeirantes, Mato Grosso do Sul.

\begin{tabular}{ccccccc}
\hline Espécie & Número indivíduos & Total $^{\mathbf{3}}$ amostra $^{-1}$ & Total $^{\mathbf{3}} \mathbf{h a}^{-\mathbf{1}}$ & Serraria & Poste & Lenha \\
\hline Angico & 10 & 2,0710 & 103,55 & 4 & 3 & 3 \\
Andira & 10 & 1,8988 & 94,94 & 0 & 2 & 8 \\
Guatambu & 10 & 2,6782 & 133,91 & 6 & 4 & 0 \\
Tarumarana & 11 & 2,2237 & 111,18 & 3 & 4 & 4 \\
Caviúna-do-cerrado & 16 & 6,3864 & 319,32 & 3 & 13 & 0 \\
Cumbaru & 20 & 4,4693 & 223,46 & 5 & 15 & 0 \\
Balsaminho & 10 & 0,9243 & 46,21 & 2 & 8 & 0 \\
Marinheiro & 16 & 1,6012 & 80,06 & 10 & 6 & 0 \\
Pau-terra & 27 & 6,2294 & 311,47 & 11 & 8 & 8 \\
Cotó & 22 & 0,9577 & 47,88 & 4 & 0 & 18 \\
Quaresmeira & 16 & 0,9222 & 46,11 & 3 & 0 & 13 \\
Catiguá & 29 & 3,7737 & 188,68 & 20 & 9 & 0 \\
Pau-doce & 41 & 4,8263 & 241,31 & 28 & 0 & 13 \\
Pimenta-de-macaco & 22 & 1,1478 & 57,39 & 22 & 0 & 0 \\
Subtotal & 260 & $40,11(59,85 \%)$ & 2005,50 & 121 & 72 & 67 \\
Demais espécies & 135 & $26,9028(40,15 \%)$ & 1345,14 & 40 & 55 & 40 \\
\hline Total & 395 & $67,0128(100 \%)$ & 3350,64 & 161 & 127 & 107 \\
\hline
\end{tabular}


Fonte: Autores.

As espécies de madeira qualificada para serraria, de maior valor, representaram 161 indivíduos (40,76\%), seguido por 127 indivíduos (32,15\%) a serem utilizados como estacas, postes e esticadores; os demais, 107 (27,09\%), se destinavam à lenha. Entre estas, as que contribuíram com o maior volume total foram Dalbergia miscolobium, madeira de ótima qualidade, utilizada para móveis e acabamento, e Qualea grandiflora, madeira de pouco valor comercial (Useful Tropical Plants, 2019), ambas consideradas pioneiras (Lorenzi, 2016; 2020).

Para o volume destinado para serraria, destacam-se Trichilia pallida, espécie secundária com madeira de bom valor econômico e, Vochysia tucanorum (pioneira) e Xylopia aromatica (pioneira/secundária), ambas de madeira de baixa qualidade (Lorenzi, 2016, 2020; Useful Tropical Plants, 2019). Em relação a fabricação de postes e esticadores, Dalbergia miscolobium, considerada uma espécie pioneira de bom valor comercial, e Dipteryx alata, clímax, com madeira resistente e dura, considerada de excelente qualidade e valor comercial (Useful Tropical Plants, 2019), se destacam. Já para uso como lenha, Rudgea viburnoides, que ocorre em formação secundária, porém de madeira de pouco valor; Pleroma granulosum, de formação secundária e madeira bem valorizada; e, Vochysia tucanorum, que ocorre em formação primária e secundária, porém, de madeira considerada ruim, são as mais importantes.

Estes dados indicam que o retorno financeiro da exploração da madeira é um incentivo aos processos de supressão vegetal no bioma, pois o lucro obtido é significativo, apesar do processo poder gerar áreas de pastagens de baixa produtividade, fator derivado do tipo de solo (Brito, 2016; Ramos et al., 2017; SEMA-DF, 2017; TNC, 2019). Na região de estudo, Latossolos vermelhos distróficos e Neossolos Quartzarênicos são os predominantes, considerados de baixa fertilidade natural e propícios a uma série de problemas ambientais, tais como erosão e rápida perda de fertilidade, quando manejados inadequadamente.

De acordo com dados de Dias-Filho (2017), a maior parte das pastagens no Cerrado apresentam diferentes níveis de degradação, resultado do uso incorreto do solo, com prejuízos para toda a sociedade e ambiente. Desta maneira, apesar da qualidade madeireira (explorada a médio prazo, através de processos de manejo florestal), os proprietários normalmente fazem a opção por um retorno de curto espaço de tempo, retirando a madeira e, posteriormente, implantando pastagens exóticas para a criação de gado.

\section{Conclusão}

Os resultados indicaram a presença de 395 indivíduos, pertencentes a 21 famílias e 49 espécies, com maior índice do valor de importância sendo encontrado para Vochysia tucanorum (Vochysiaceae). Fabaceae foi a família mais representativa, com 12 espécies, seguida por Annonaceae, Bignoniaceae e Vochysiaceae, com três espécies cada. O volume total de madeira encontrado foi de $3350,64 \mathrm{~m}^{3}$, com $59,85 \%$ dos fustes mensurados podendo ser destinados à serraria e demonstrando o potencial madeireiro da área.

A caracterização do potencial madeireiro e não madeireiro é uma importante ferramenta para o direcionamento de uma possível utilização das espécies e, como consequência, subsídio para trabalhos futuros e manejo florestal sustentável, contribuindo para a manutenção da vegetação do bioma. Assim, conhecer e valorizar as espécies encontradas no Cerrado é fundamental para a preservação dos fragmentos restantes, evitando a sua simples substituição por outras atividades, muitas vezes com menor potencial de geração de renda para o proprietário rural.

\section{Agradecimentos}

Os autores agradecem a Universidade Anhanguera-Uniderp pelo financiamento do projeto GIP (Grupo 
Interdisciplinar de Pesquisa) e pagamento de bolsa de estudo, a Coordenação de Aperfeiçoamento de Pessoal de Nível Superior (CAPES) pela bolsa de estudos (Código de Financiamento 001) e ao Conselho Nacional de Desenvolvimento Científico e Tecnológico $(\mathrm{CNPq})$, pela bolsa de Produtividade em Pesquisa.

\section{Referências}

Alho, C. J. R. \& Martins, E. S. (1995). De grão em grão, o Cerrado perde espaço (Cerrado-Impactos do Processo de Ocupação). Brasília: WWF-Fundo Mundial para a Natureza.

Alvarenda, F. Q., Royo, V. A., Mota, B. F. C., Laurentiz, R. S., Menezes, E. V., Melo Junior, A. F. \& Oliveira, D. A. (2015). Atividade antinociceptiva e antimicrobiana da casca do caule de Psidium cattleyanum Sabine. Revista Brasileira de Plantas Medicinais, 17(4), $1125-1133$.

Balduino, A. P. C., Souza, A. L., Meira Neto, J. A. A., Silva, A. F. \& Silva Júnior, M. C. (2005). Fitossociologia e análise comparativa da composição florística do Cerrado da flora de Paraopeba-MG. Revista Árvore, 29, 25-34.

Bezerra, J. S., Linhares, K. V., Calixto Júnior, J. T., Duarte, A. E., Mendonça, A. C. A. M., Pereira, A. E. P., Batista, M. E. P., Bezerra, J. W. A., Campos, N. B., Pereira, K. S., Sousa, J. D. \& Silva, M. A. P. (2020). Floristic and dispersion syndromes of Cerrado species in the Chapada do Araripe, Northeast of Brazil. Research, Society and Development, 9(9), e864997934.

Brasil (2006). Ministério do Meio Ambiente. 2006. Resolução Conama nº 379, de 19 de outubro de 2006. Cria e regulamenta sistema de dados e informações sobre a gestão florestal no âmbito do Sistema Nacional do Meio Ambiente - SISNAMA. Diário Oficial (da) República Federativa do Brasil, Brasília, DF, de 20 de outubro de 2006 .

Braun-Blanquet, J. (1979). Fitosociologia: bases para el estudio de las comunidades vegetales. (3a ed.) Madrid: Aum. Blume.

Bridgewater, S., Ratter, J. A. \& Ribeiro, J. F. (2004). Biogeographic patterns, $\beta$-diversity and dominance in the cerrado biome of Brazil. Biodiversity and Conservation, 13, 2295-2317.

Brito, A. (2016). Heterogeneidade espaço-temporal do desmatamento do Cerrado brasileiro: estimativas e cenários de emissões de carbono. 156f. Tese (Doutorado em Ciência do Sistema Terrestre). Instituto Nacional de Pesquisas Espaciais, São José dos Campos.

Camilotti, D. C., Pagotto, T. C. S. \& Araújo, A. C. (2011). Análise da vegetação arbórea de um remanescente de Cerradão em Bandeirantes, Mato Grosso do Sul, Brasil. Iheringia, Série Botânica, 66(1), 31-46.

Carvalho, P. E. R. (2007). Jatobá-do-Cerrado Hymenaea stigonocarpa: Taxonomia e Nomenclatura. Circular Técnica Embrapa Florestas. Colombo, (133), 18 .

Climate-Data. Clima: Bandeirantes (2017). https://pt.climate-data.org/location/316372/

CNCFlora. Centro Nacional de Conservação da Flora (2018). Lista Vermelha. Instituto de Pesquisas Jardim Botânico do Rio de Janeiro. http://cncflora.jbrj.gov.br/portal/pt-br/listavermelha

Coradin, L., Siminski, A. \& Reis, A. (Eds.) (2011). Espécies nativas da flora brasileira de valor econômico atual ou potencial: plantas para o futuro. MMA.

Costa, F. G., Costa, V. S., Martins, I. S., Brito, E. C., Soares, K. S. A., Castro, Y. A. A. \& Castro, I. F. A. (2020). Knowing Cerrado: field classes and their importance for environmental knowledge and preservation. Research, Society and Development, 9(10), e1589108201.

Costa, R. B. (Org.) (2003). Fragmentação florestal e alternativas de desenvolvimento rural na Região Centro-Oeste. UCDB.

Davide, A. C., Faria, J. M. R. \& Botelho, S. A. (1995). Propagação de espécies florestais. UFLA.

Dias-Filho, M. B. (2017). Degradação de pastagens: o que é e como evitar. Embrapa.

Durigan, G., Contieri, W. A., Franco, G. A. D. C. \& Garrido, M. A. O. (1998). Indução do processo de regeneração da vegetação de cerrado em área de pastagem, Assis, SP. Acta Botanica Brasilica, 12, 421-429.

Durigan, G. (2006). Métodos para análise de vegetação arbórea. In: Cullen Junior, L., Rudran, R. \& Valladares-Pádua, C. (Orgs.). Métodos de Estudos em Biologia da Conservação e Manejo da Vida Silvestre. Curitiba: UFPR/Fundação Boticário de Proteção à Natureza. $455-478$.

Elias, V. C. (2009). Inventário florestal e uso do solo numa propriedade rural sob domínio do Cerrado em Paranã, TO. 30f. Monografia (Graduação em Engenharia Florestal) — Universidade Federal Rural do Rio de Janeiro, Seropédica.

Felfili, J. M., Nascimento, A. R. T., Fagg, C. W. \& Meirelles, E. M. (2007). Floristic composition and community structure of a seasonally deciduous forest on limestone outcrops in Central Brasil. Revista Brasileira de Botânica 30, 611-621.

Felfili, J. M., Silva Júnior, M. C., Sevilha, A. C., Fagg, C. W., Walter, B. M. T., Nogueira, P. E. \& Rezende, A. V. (2004). Diversity, floristic and structural patterns of cerrado vegetation in Central Brazil. Plant Ecology 175, 37-46.

Gama, J. R. V., Botelho, S. A., Bentes-Gama, M. M. \& Scolforo, J. R. S. (2003). Estrutura e potencial futuro de utilização da regeneração natural de floresta de várzea alta no município de Afuá, estado do Pará. Ciência Florestal, 13, 71-82.

Gottlieb, O. R. \& Borin, M. R. M. B. (1994). The diversity of plants: Where is it? Why is it there? What will it become? Anais da Academia Brasileira de Ciências, 66, 55-83. 
Grecchhi, R. C., Gwyn, Q. H. J., Bénié, G. B., Formaggio, A. R. \& Fahl, F. C. (2014). Land use and land cover changes in the Brazilian Cerrado: A multidisciplinary approach to assess the impacts of agricultural expansion. Applied Geography, 55, 300-312.

Hack, C., Longhi, S. J., Boligon, A. A., Murabi, A. B. \& Pauleski, D. T. (2005). Análise fitossociológica de um fragmento de floresta estacional decidual do município de Jaguari, RS. Ciência Rural, 35, 1083-1091.

Hahn, C. M., Silva, A. N., Oliveira, C., Amaral, E. M., Valle, J. F. C., Rodrigues, M. S. \& Soares, P. V. (Coords.) (2007). Roteiro para a elaboração de projetos de recuperação florestal para o Fundo Estadual de Recursos Hídricos - Fehidro. São Paulo: SMA/FF.

Haridasan, M. \& Araújo, G. M. (1988). Aluminium-accumulating species in two forest communities in the Cerrado region of central Brazil. Forest Ecology and Management, 24, 15-26.

Husch, B., Miller, I. C. \& Beers, T. W. (1982). Forest mensuration. J. Wiley.

IBGE. Instituto Brasileiro de Geografia e Estatística (2006). Amazônia Legal - Fronteira Agrícola. http://www.ibge.gov.br/home/geociencias/geografia/mapas _doc3.shtm

Jácome, R. L. R. P., Oliveira, V. D. C., Oliveira, M. A. T., Mariano, M. C. F. \& Oliveira, A. B. (2010). Estudo farmacognóstico comparativo das folhas de Davilla elliptica A. St.-Hil. e D. rugosa Poir., Dilleniaceae. Revista Brasileira de Farmacognosia, 20, 390-396.

Kershaw Junior, J. A., Ducey, M. J., Beers, T. W. \& Hush, B. (2016). Forest mensuration. (5a ed.), Hoboken: Wiley-Blackwell.

Lewis, G.P. (2000). Legumes of Bahia. Richmond: Kew Publishing/Royal Botanic Gardens.

Lewis, G., Schrire, B., Mackinder, B. \& Lock, M. (Eds) (2005). Legumes of the World. Cambridge: Kew Publishing, Royal Botanic Gardens.

Lima, M. S., Damasceno Júnior, G. A. \& Tanaka, M. O. (2010). Aspectos estruturais da comunidade arbórea em remanescentes de floresta estacional decidual, em Corumbá, MS, Brasil. Revista Brasileira de Botânica, 33, 437-453.

Lima, E. M., Rezende, A. V., Oliveira, L. S. B.; Azevedo, G. B. \& Matos, N. M. (2014). Diversidade e riqueza em área de Cerrado sensu stricto após diferentes intensidades de exploração da vegetação. Simpósio Brasileiro de Pós-Graduação em Ciências Florestais, 8, 2014, Recife. Anais... Recife: PPGCF. p. 446-449.

Lopes, T. C., Gonçalves, J. R. S., Souza, N. S., Moraes, D. F. C., Amaral, F. M. M. \& Rosa, I. G. (2011). Avaliação moluscicida e perfil fitoquímico das folhas de Caryocar brasiliense Camb. Cadernos de Pesquisa, 18(3), 23-30.

Lopes, S. F., Vale, V. S., Oliveira, A. P. \& Schiavini, I. (2011). Análise comparativa da estrutura e composição florística de cerrado no Brasil central. Interciencia, 36, 8-15.

Lorenzi, H. (2016). Árvores brasileiras: Manual de identificação e cultivo de plantas arbóreas do Brasil. (5a ed.), Plantarum.

Lorenzi, H. (2020). Árvores brasileiras: Manual de identificação e cultivo de plantas arbóreas do Brasil. 1. (8a ed.), Plantarum.

Martinelli, G., \& Moraes, M. A. (Orgs.) (2013). Livro vermelho da flora do Brasil. Instituto de Pesquisas Jardim Botânico do Rio de Janeiro.

Martins, F. R. (1993). Estrutura de uma floresta mesófila. (2a ed.), Editora UNICAMP.

Martins, R. C. C. (2004). Germinação e crescimento inicial de três espécies pioneiras do Bioma Cerrado no Distrito Federal, Brasil. 141f. Tese (Doutorado em Ciência Florestal) — Universidade Federal de Viçosa, Viçosa.

Mattos, N. F. (1979). O gênero Andira Lam. (Leguminosae Papilionoideae) no Brasil. Acta Amazonica, 9, 241-266.

Mendonça, R. A. A. \& Costa, C. G. (2018). O negligenciado Cerrado paulista. Revista Brasileira de Geografia, 63, 129-155.

Menezes Filho, A. C. P. \& Castro, C. F. S. (2019). Identificação das classes de metabólitos secundários em extratos etanólicos foliares de Campomanesia adamantium, Dimorphandra mollis, Hymenaea stigonocarpa, Kielmeyera lathrophytum e Solanum lycocarpum. Estação Científica (UNIFAP), 9(1), 89-101.

Monteiro, F. N. \& Falcão, K. S. (2019). Resiliência em fragmento perturbado no bioma Cerrado. Research, Society and Development, 9(3), e33932351.

Moraes, L. F. D., Assumpção, J. M., Pereira, T. S. \& Luchiari, C. (2013). Manual técnico para a restauração de áreas degradadas no Estado do Rio de Janeiro. Rio de Janeiro: Jardim Botânico do Rio de Janeiro.

Moro, M. F. \& Martins, F. R. (2011). Métodos de levantamento do componente arbóreo/arbustivo. In: Felfili, J. M., Eisenlohr, P. V., Melo, M. M. R. F., Andrade, L. A. \& Meira Neto, J. A. (Eds.). Fitossociologia no Brasil: Métodos e estudos de casos. Viçosa: Editora UFV, 174-212.

Mueller-Dombois, D. \& Ellenberg, H. (2003). Aims and methods of vegetation ecology. (2a ed.), The Blackburn Press.

Oliveira, A. K. M. \& Resende, U. M. (2012). Composição florística do Parque Estadual Matas do Segredo, localizado na área urbana do Município de Campo Grande, Mato Grosso do Sul. Revista da Sociedade Brasileira de Urbanização Urbana, 7(3), 57-74.

Oliveira, A. K. M., Resende, U. M. \& Schleder, E. J. D. (2014). Espécies vegetais e suas síndromes de dispersão em um remanescente de cerrado (sentido restrito) do município de Campo Grande, Mato Grosso do Sul. Ambiência, 10(2), 565-580.

Peres, M. K. (2016). Estratégias de dispersão de sementes no Bioma Cerrado: considerações ecológicas e filogenéticas. 360f. Tese (Doutorado em Botânica) Universidade de Brasília, Brasília. 
Ramos, T. C. P. M., Souza, E. F., Pina, J. C., Facco, J. T., Cassol, A. L., Santos, M. N. \& Santos, M. S. M. (2017). Caracterização química de um solo de cerrado stricto sensu em Dourados-MS. Simpósio de bioquímica e biotecnologia, 6, 20-22 set. 2017, Londrina. Anais... Londrina: SIMBBTEC. p. 1-4.

Reis, A. \& Kageyama, P. Y. (2003). Restauração de áreas degradadas utilizando interações interespecíficas. In: Kageyama, P. Y., Oliveira, R. E., Moraes, L. F. D., Engel, V. L. \& Gandara, F. B. (Eds.). Restauração Ecológica de Ecossistemas Naturais. Botucatu: FEPAF. p. 91-110.

Reis, C. A. F., Souza, A. M., Mendonça, E. G., Gonçalvez, F. R., Melo, R. M. G. \& Carvalho, D. (2009). Diversidade e estrutura genética espacial de Calophyllum brasiliense Camb. (Clusiaceae) em uma floresta paludosa. Revista Árvore, 33, 265-275.

Ribeiro, J. F. \& Walter, B. M. T. (2008). As principais fitofisionomias do bioma Cerrado. In: Sano, S. M., Almeida, S. P. \& Ribeiro, J. F. Cerrado: ecologia e flora. Rio de Janeiro: Embrapa. p. 152-212.

Rizzini, C. T. (1978). Árvores e madeiras úteis do Brasil: Manual de dendrologia brasileira. (2a ed.), Editora Edgard Blucher.

Rizzini, C. T. \& Mors, W. B. (1995). Botânica econômica brasileira. (2a ed.), Âmbito Cultural.

Rodrigues, R. R., Torres, R. B., Mattes, L. A. F. \& Penha. A. S. (2004). Tree species sprouting from root buds in a semideciduous forest affected by fires. Brazilian Archives of Biology and Technology, 47(1), 127-133.

Rocha, C. C. C. (2011). Estimativa de volume, biomassa e carbono da vegetação lenhosa de floresta estacional no estado de Goiás. 70f. Dissertação (Mestrado em Ciências Florestais) — Universidade de Brasília, Brasília.

Rondon Neto, R. M., Santos, J. S., Silva, M. A. \& Koppe, V. C. (2010). Potencialidades de uso de espécies arbustivas e arbóreas em diferentes fisionomias de cerrado, em Lucas do Rio Verde/MT. Revista de Biologia e Ciências da Terra, 10, 113-126.

Saccaro Junior, N. L. (2011). A regulamentação de acesso a recursos genéticos e repartição de benefícios: disputas dentro e fora do Brasil. Ambiente \& Sociedade, 14, 229-244.

Santos, R. M. \& Vieira, F. A. (2005). Análise estrutural do componente arbóreo de três áreas de cerrado em diferentes estágios de conservação no município de Três Marias, Minas Gerais, Brasil. Cerne, 11, 399-408.

Sartorelli, P. A. R. \& Campos Filho, E. M. (2017). Guia de plantas da regeneração natural do Cerrado e da Mata Atlântica. Agroicone.

SEMAC. Secretaria de Estado de Meio Ambiente, do Planejamento, da Ciência e Tecnologia (2011). Caderno Geoambiental das Regiões de Planejamento de Mato Grosso do Sul. Campo Grande: SEMAC/SEPLAN.

SEMA-DF. Secretaria de Estado do Meio Ambiente do Distrito Federal (2017). Plano recupera Cerrado: uma avaliação das oportunidades de recomposição para o Distrito Federal. Brasília: SEMA-DF.

Silva, D. H. S., Castro-Gamboa, I. \& Bolzani, V. S. (2010). Plant diversity as a tool for prospecting potential therapeutic drugs. In: Mander, L. \& Liu, H-W. Comprehensive Natural Products II: Chemistry and Biology. Kidlington: Elsevier Sci \& Tech Book Div. 95-133.

Silva, I. P. (2014). Avaliação da entomofauna em frutos de espécies florestais do Cerrado. 44f. Dissertação (Mestrado em Ciências Florestais e Ambientais) Universidade Federal de Mato Grosso, Cuiabá.

Silva, L., Costa, D. A., Santo Filho, K. E., Ferreira, H. D. \& Brandão, D. (2002). Levantamento florístico e fitossociológico em duas áreas de cerrado sensu stricto no Parque Estadual da Serra de Caldas Novas, Goiás. Acta Botanica Brasilica, 16, 43-53.

Silva, M. A., Silva, G. A., Marques, M. J., Bastos, R. G., Silva, A. F., Rosa, C. P. \& Espuri, P. F. (2016). Triagem fitoquímica, atividade antioxidante e leishmanicida do extrato hidroetanólico 70\% (v/v) e das frações obtidas de (Annona crassiflora Mart.). Revista Fitos, 10(4), 505-517.

Silva, W. R. (2003). A importância das interações planta-animal nos processos de restauração. In: Kageyama, P. Y., Oliveira, R. E., Moraes, L. F. D., Engel, V. L. \& Gandara, F. B. (Eds.). Restauração ecológica de ecossistemas naturais. Botucatu: FEPAF. 77-90

Silveira, E. P. (2010). Florística e estrutura da vegetação de cerrado sensu stricto em terra indígena no noroeste do Estado de Mato Grosso. 62f. Dissertação (Mestrado em Ciências Florestais e Ambientais) - Faculdade de Engenharia Florestal, Universidade Federal de Mato Grosso, Cuiabá.

Siqueira, A. S., Araújo, G. M. \& Shiavini, I. (2009). Estrutura do componente arbóreo e características edáficas de dois fragmentos de floresta estacional decidual no vale do rio Araguari, MG. Acta Botanica Brasilica, 23, 10-21.

SMA. Secretaria de Estado do Meio Ambiente. Resolução SMA n. 57, de 5 de junho de 2016 (2016). Publica a segunda revisão da lista oficial das espécies da flora ameaçadas de extinção no Estado de São Paulo. In: Diário Oficial do Estado de São Paulo, Poder Executivo, São Paulo, SP, 07 jun. 2016. p. 69-71.

Soares, C. P. B., Paula Neto, F. \& Souza, A. L. (2011). Dendrometria e inventário florestal. (2a ed.), Editora UFV.

TNC. The Nature Conservancy (2019). Incentivos para produção de soja sustentável no Cerrado. São Paulo: TNC.

Useful Tropical Plants (2019). Database Search. http://tropical.theferns.info/query.php

Valli, M., Young, M. C. M. \& Bolzani, V. (2016). A beleza invisível da biodiversidade: O táxon Rubiaceae. Revista Virtual de Química, 8(1), 296-310.

Weiser, V. L. \& Godoy, S. A. P. (2001). Florística em um hectare de cerrado stricto sensu na ARIE-Cerrado Pé-de-Gigante, Santa Rita do Passa Quatro, SP. Acta Botanica Brasilica, 15, 201-212. 